\title{
Algumas perspectivas para o estudo das mídias nas diferentes regiões do Brasil
}

Antonio HOHLFELDT ${ }^{1}$

Resumo:

O artigo conceitua o termo região e faz rápido esboço da evolução de seu sentido nos vários campos de conhecimento. Depois, centra sua atenção sobre a região sul e procura apresentar o surgimento e organização desta região, com a popularização de seu gentílico - gaúcho - assim como uma rápida abordagem de seu desenvolvimento cultural, o que virá a se refletir nos seus atuais meios de comunicação, empresas, produtos e circulação.

Palavras-chave:

Região. Gaúcho. Produção cultural. Meios de comunicação. Pesquisa em comunicação.

\section{Some perspectives for the study of media in the different regions of Brazil}

\begin{abstract}
:
This paper develope the concept of region e his history on different fields of knowledge. The text think about the South of Brazil and presents the appearance of the gaucho typeman. The text think about the cultural development of these region which reflects on his mass communications systems and business.

Keywords:

Region. Gaucho. Cultural production. Mass communication. Communication research.

\section{Algunas perspectivas para el estudio de los medios en las diferentes regiones de Brasil}

Resumen:

Este texto desarolla el concepto de region y presenta una pequeña historia Del mismo. Después, destaca La region sur de Brasil y su tipo característico, el gaucho. Presenta aún El desarollo de La cultura regional y sus reflejos sobre la organización y producción de los aparatos de la cultura de massas.

Palabras clave:

Región. Gaucho. Producción cultural. Comunicación de massas. Pesquisa sobre comunicación.

\section{INTRODUÇÃO}

O conceito de região e/ou de regional, que se menciona no título deste artigo, é uma construção social e mental, excludente e includente, ao mesmo tempo, ou seja, está-se a trabalhar com um conceito ambíguo. Por isso mesmo, ele é um conceito polissêmico: considerando a região sempre como parte, estamos nos referindo a um outro que seria, pretensamente, o todo, de que a região faria parte. Talvez justamente por ser parte, e não todo, muitas vezes, a região é pensada desqualificadamente, como algo menor. Devemos considerar a região, contudo, como algo diferente, não mais que

\footnotetext{
${ }^{1}$ Professor do Programa de Pós-Graduação em Comunicação Social/FAMECOS e do Programa de PósGraduação em Literatura/Escrita Criativa, da Faculdade de Letras/FALE, ambas da PUCRS. Pesquisador do $\mathrm{CNPq}$, integrante do Instituto Histórico e Geográfico do Rio Grande do Sul. Ex-presidente da INTERCOM, integra, atualmente, a diretoria da ALCAR.
} 
isso, e, sobretudo, levarmos em conta que tudo o mais que pudermos dizer em torno dela e sobre ela, será apenas uma construção social a que deveremos, evidentemente, estar atentos ${ }^{2}$.

\title{
A construção do conceito de região
}

O conceito de região deriva do verbo latim regere. O termo regio (e sua derivação regione) representava a denominação, no antigo Império Romano, daquelas áreas que, mesmo possuindo alguma autonomia de decisão, estavam vinculadas à administração central de Roma quanto a seus aspectos mais decisivos. Possuía, portanto, uma conotação eminentemente política (CORREA, 1997).

Empregado originalmente no sentido de extensão, o termo região ficou ligado à noção de identidade territorial, o que tornava possível criar um limite (fronteira) demarcatório que representasse a área de presença desta identidade.

Um outro conceito importante vai se desenvolver, a partir do século XIX, com base na nova ciência da Geografia que, por seu lado, vai se remeter aos conceitos da Geologia. É assim que nasce o conceito de região natural, referenciada às bacias hidrográficas como seus demarcadores naturais (KLARMANN, 1999). Cada região, então, teria um caráter particular e caberia à geografia desvendar esta combinação e os fatores responsáveis por tal configuração, utilizando técnicas descritivas, aproximandose ao máximo do objeto para captar a sua identidade.

\section{Recuperando algumas perspectivas}

O princípio estendeu-se: aplicou-se às Ciências Sociais em geral, chegou aos estudos sobre a Cultura e, certamente, pode ser aqui utilizado.

Luiz Beltrão, em conferência no II Congresso da UCBC - União Cristã Brasileira de Comunicação, afirmava:

\begin{abstract}
Uma região é o palco em que, por excelência, se definem os diferentes sistemas de comunicação cultural, isto é, do processo humano de intercâmbio de idéias, informações e sentimentos, mediante a utilização de linguagens verbais e não-verbais e de canais naturais e artificiais empregados para a obtenção daquela soma de conhecimentos e experiências necessária à promoção da convivência ordenada e do bem-estar coletivo. (BELTRÃO, 2006, p. 73).
\end{abstract}

\section{E acrescentava:}

\footnotetext{
${ }^{2}$ Comecei a desenvolver estas ideias a partir de HOHLFELDT, Antonio - "Comunicação e cultura regional na sociedade digital", apresentado no Congresso da INTERCOM SUL, entre 10 e 12 de maio de 2007, na Universidade de Passo Fundo.
} 
Uma região se define antropossociologicamente pelos seus habitantes e sua estrutura social: população, raça, língua, crenças, costumes e tradições, organização familiar e política, economia, maior ou menor grau de abertura às influências exteriores, vias de acesso e meios de comunicação disponíveis. (BELTRÃO, 2006, p. 73).

Recentemente, Silviano Santiago, falando a respeito do tema, registrava:

Na política contemporânea, a questão regional fica aquém e além do nacional; fica também aquém e além do universal globalizado. A dubiedade espacial - decorrente da nova caracterização do objeto identidade regional, quando adjetiva a cultura, as artes ou a literatura afeta de modo sistemático a compreensão dos problemas que coloca. Antes de ser um enigma, o regional tornou-se arma de muitos gumes. (SANTIAGO, 2004, p. 97).

Em seguida, o conhecido crítico de literatura avalia a disputa que se desenvolve hoje em dia:

Com a mesma simpatia e afeto focalizemos a luta pelos valores regionais (em particular os de caráter cultural). Está sendo o modo como o artista ataca com a mesma lança os dois monstros: o monstro da globalização norte-americana e o seu filhinho monstruoso, o modelo nacionalista posto em prática [...] (SANTIAGO, 2004, p. 98).

E continua, aprofundando a questão:

A cultura regional como terreno de luta abre cisão no tecido uniforme da indústria cultural hegemônica, e se apresenta como produtora de casulos de resistência maniqueísta, o mais evidente deles sendo o da disputa entre o produto nacional e o importado, entre o produto "natural" e o enlatado, entre "caipiras" e "sertanejos". (SANTIAGO, 2004, p. 98).

Mudando um pouco o enfoque, Silviano Santiago toma um outro aspecto:

Várias e substantivas culturas nacionais, devidamente regionalizadas em outro e mais amplo contexto geográfico, o da União Européia ou o do Mercosul, por exemplo, se tornariam aliadas e mais fortes sem ter por projeto a desconstrução dos respectivos Estados-nações, como está sendo proposto pelos regionalismos. (SANTIAGO, 2004, p. 100).

Ele insiste na relatividade dos conceitos e das relações:

De acordo com esta projeção política, a palavra regional adquiriria um segundo e mais forte significado. Estaria aquém - embora no mesmo plano - da indústria cultural globalizada e estaria além - embora no mesmo plano - das culturas nacionais cujo epicentro é o Estadonação. (SANTIAGO, 2004, p. 100). 
No encaminhamento de sua conferência, Silviano Santiago prefere utilizar o conceito margem para referir essas regiões,

[...] pois não só levaria em conta a margem que o primitivo adjetivo regional representa dentro do respectivo Estado-nação, como também a margem que ganha novo significado de regional quando adjetiva o Estado-nação dentro, por exemplo, da União Europeia ou do Mercosul. Num terceiro movimento essa literatura das margens lançaria outras pontes de convivência com as diversas culturas e literaturas que se sentem também marginalizadas pelo atual processo econômico e político em marcha pelo planeta Terra [...] (SANTIAGO, 2004, p. 101).

Para que se possa bem avaliar a significação da experiência gaúcha em relação ao fluxo e refluxo da comunicação social brasileira, deve-se começar falando a respeito da região sul-rio-grandense, ou seja, do Rio Grande do Sul. Para tanto, retoma-se um antigo, mas atual texto do escritor Erico Verissimo, que assim se manifestava a respeito de sua província:

Somos uma fronteira. No século XVIII, quando soldados de Portugal e Espanha disputavam a posse definitiva deste então imenso deserto, tivemos de fazer a nossa opção: ficar com os portugueses ou com os castelhanos. Pagamos um pesado tributo de sofrimento e sangue para continuar deste lado da fronteira meridional do Brasil. Como pode você acusar-nos de espanholismo? Fomos desde os tempos coloniais até o fim do século um território cronicamente conflagrado. Em setenta e sete anos tivemos doze conflitos armados, contadas as revoluções. Vivíamos permanentemente em pé-de-guerra. Nossas mulheres raramente despiam o luto. Pense nas duras atividades da vida campeira - alçar, domar e marcar potros, conduzir tropas, sair da faina diária quebrando a geada nas madrugadas de inverno - e você compreenderá por que a virilidade passou a ser a qualidade mais exigida e apreciada do gaúcho. Esse tipo de vida é responsável pelas tendências algo impetuosas que ficaram no inconsciente coletivo desse povo, e explica a nossa rudeza, a nossa às vezes desconcertante franqueza, o nosso hábito de falar alto, como quem grita ordem, dando não raro aos outros a impressão de que vivemos num permanente estado de cavalaria. A verdade, porém, é que nenhum dos heróis autênticos do Rio Grande que conheci jamais proseou, jamais se gabou de qualquer ato de bravura seu. Os meus coestaduanos que, depois da vitória da Revolução de 30 , se tocaram para o Rio, fantasiados, e amarraram seus cavalos no obelisco da Avenida Rio Branco - esses não eram gaúchos legítimos, mas paródias de opereta. (VERÍSSIMO, 1969, p.3-4).

Esse texto, embora datado, é extremamente atual. Ele não deixa de ratificar alguns mitos: certa cultura de fronteira; a opção pelo Brasil; um tributo de sofrimento; o contínuo clima beligerante a que foi condenado o Rio Grande, inclusive pela 
permanente requisição de tropa e de animais para as diferentes guerras e revoluções; a dureza dos trabalhos campeiros; a psicologia algo rude do gaúcho; sua humildade. Contudo, ao mesmo tempo, o autor de "O tempo e o vento" não deixa de criticar certa vaidade e determinada nostalgia que marcariam a cultura sul-rio-grandense nos tempos contemporâneos, tendência a que se oporia o escritor.

\title{
O conceito de gaúcho
}

Para que melhor se entenda, portanto, o que tem ocorrido com o Rio Grande do Sul, talvez semelhante a algumas poucas outras províncias do país, é necessário revisarse alguma coisa de história, de antropologia e de sociologia.

É, sobretudo, fundamental lembrar-se também da velha e riquíssima lição de Augusto Meyer, ao final de seu "Gaúcho - História de uma palavra":

\begin{abstract}
As características com que se pretende estereotipar esse fantasma intemporal desenham quase sempre um perfil demarcado e simplista dessa coisa tão vaga em si mesma. O estudo semântico da palavra gaúcho vem mostrar como é difícil manter, na historiografia riograndense, os velhos preconceitos de uma homogeneidade cultural cultural no sentido sociológico - que nunca existiu. Qualquer tentativa de interpretação de nossa história deverá levar em conta, como fator, básico, o critério de aculturação. Aceitar passivamente o prejuízo da homogeneidade social ou política de um grupo rio-grandense, dentro de outro bloco luso-brasileiro, caracterizado e definido por simples idealização do autor, e conforme as suas preferências, é prosseguir no cultivo de uma história em que tudo parece acontecer por obra e graça de uma Divina Providência Gaúcha, que desde o começo decretou as coisas na mesma ordem rígida. (MEYER, 1960, p. 42).
\end{abstract}

O que Meyer está preocupado em mostrar é que a designação gaúcho tornou-se um coletivo para todos aqueles que chegaram e se fixaram no território sul-riograndense. Portanto, trata-se não apenas de uma designação de certo segmento de sulrio-grandenses, mas de todo o seu conjunto. Preocupa-se ele, igualmente, em considerar que não se deve distingui-los tão ostensivamente do restante dos brasileiros. Esse texto, relativamente datado, mostra-nos a tentativa de ultrapassar certo preconceito, em construção, da gauchividade em relação ao que então nascia: o Movimento Tradicionalista Gaúcho, iniciado em 1947, dentre outros, por Barbosa Lessa e Paixão Côrtes, tentativa de se opor, tanto à tendência de dissolução da regionalidade no nacionalismo, vigente desde o Estado Novo de 1937, quanto à nascente presença do multinacionalismo norte-americano, crescente a partir da industrialização dos anos 30 do século XX, acelerado no pós-II Grande Guerra. 
Algumas décadas depois, essa perspectiva seria revista, ao menos parcialmente.

$\mathrm{Se}$

\begin{abstract}
a nação é um produto cultural que surge na Europa a partir do fim do século XVIII e que se constitui (...) em uma comunidade política imaginada, nesse processo de construção histórica, a relação entre o velho e o novo, o passado e o presente, a tradição e a modernidade é uma constante e se reveste de importância fundamental (OLIVEN, 1992, p. 15).
\end{abstract}

$\mathrm{Na}$ verdade, o Brasil experimenta esse conceito a partir da segunda década do século XX, com o chamado Modernismo. Mas, ao mesmo tempo, reconhece e valoriza a regionalização: "o regionalismo, nessa perspectiva, pode ser encarado como um campo de disputas no qual grupos com diferentes posições e interesses se enfrentam" (OLIVEN, 1992, p. 19), perspectiva que se vale do conceito de campo, na acepção de Pierre Bourdieu, de que se apropria o pesquisador sul-rio-grandense, mostrando que o regionalismo se trata, de qualquer modo, de uma construção simbólica e, como tal, cultural, que se faz sob determinado(s) contexto(s) social(ais) e histórico(s).

Oliven salienta que

a evocação da tradição - entendida como um conjunto de orientações valorizativas consagradas pelo passado - se manifesta freqüentemente em época de processos de mudança social, tais como a transição de um tipo para outro de sociedade, crises, perda de poder econômico e/ou político, etc. (OLIVEN, 1992, p. 21).

Historicamente, o autor identifica diferentes momentos de surgimento dessa tendência, desde o pós-Grande Revolução de 1835-1845, como espécie de compensação psicológica da derrota sofrida contra o Império; a passagem do século XIX para o XX, quando experimenta profundas mudanças com a industrialização nascente, que perdurará até os anos 20/30 do novo século. Mais tarde, na década de 50, com a chegada da indústria cultural norte-americana, no bojo do pós-guerra e, enfim, nas décadas de 70-80, com o ressurgimento do nativismo, forma específica do tradicionalismo, quando se tenta enfrentar a perda de identidade, duplamente motivada pela centralização social e econômica, além de política, implantada pela ditadura de 64 e, ao mesmo tempo, o forte crescimento da indústria cultural massiva, em especial a criação das grandes redes televisivas, que centralizam toda e qualquer possibilidade de produção, difusão e valorização culturais.

Oliven, opondo-se àquela perspectiva de Meyer, afirma que se trata de "uma construção de identidade que exclui mais que inclui, deixando fora a metade do 
território sul-rio-grandense e grande parte de seus grupos sociais" (OLIVEN, 1992, p. 100).

No entanto, Nilda Jacks, que tem dedicado pesquisas ao estudo em torno das relações entre a mídia massiva e os produtos culturais regionalizados do Rio Grande do Sul, distingue entre tradicionalismo e nativismo. Citando Glaucus Saraiva, mostra que o tradicionalismo

é um sistema organizado e planificado de culto, prática e divulgação desse todo que chamamos tradição. Obedece a uma hierarquia própria, possui alto programa contido em sua Carta de princípios, que deve, na medida do possível, realizar e cumprir. Tradição, comparativamente, é o campo das culturas gauchescas [sic]. Tradicionalismo, a técnica de criação, semeadura, desenvolvimento e proteção de suas riquezas naturais, através de núcleos que se intitulam CTGs. (JACKS, 1998, p. 43).

Ao contrário, o nativismo "é um movimento predominantemente musical, desencadeado pela criação de festivais, de cunha nativista, na década de 1970, que alcançou seu auge nos anos 80" (JACKS, 1998, p. 44). Pode-se dizer que, por extensão, nos dias de hoje, e a partir do movimento de produção musical, portanto, o nativismo expandiu-se para outros campos da produção cultural, inclusive em práticas literárias e de publicidade, na produção literária e de artes plásticas, atingindo todos os segmentos da economia do Rio Grande do Sul, pois chega até o artesanato - o mais variado possível - com produtos de couro, madeira, tecido, além de objetos produzidos a partir de matérias-primas locais, como ossos de animais - em especial o gado vacum - e vegetais, aproximando-se e misturando-se com as práticas tradicionalistas, na medida em que as tecnologias da indústria cultural permitem tais cruzamentos, inventando aquilo que se tem denominado, popularmente, e não sem uma certa crítica irônica, de gaúcho de fim-de-semana, na medida em que habitantes das grandes cidades dirigem-se para as sedes dos CGTs, onde integram diferentes piquetes ${ }^{3}$ tradicionalistas, vestidos dentro das alegadas tradições gaúchas e ali tomam mate, comem churrasco, declamam poemas e ouvem música nativista, quando não participam de bailes, denominados fandangos.

É, pois, sob tais perspectivas iniciais que se devem projetar estudos a respeito das mídias regionais. Há que se levar em conta que existe a regionalização do Brasil em relação à América do Sul, e desta em relação ao mundo. Mas há, também, uma

\footnotetext{
${ }^{3}$ Denominação de pequenos grupos de tradicionalistas que não chegam a constituir propriamente um Centro de Tradições Gaúchas. Por vezes, a reunião de vários piquetes termina por gerar um CTG.
} 
regionalização do Rio Grande do Sul em relação ao país brasileiro. Mais que isso, devese lembrar que o próprio estado sul-rio-grandense é formado por diferentes regiões culturais, como já indicou Barbosa Lessa, quando Secretário de Estado da Cultura. Para ele, como explica Caroline Kraus Luvizotto,

\begin{abstract}
a cultura gaúcha e suas expressões estão alicerçadas em tradições, em conhecimentos obtidos pela convivência em grupo, somados a diversos elementos, entre eles, os históricos e os sociológicos. Seus legados e sua tradição são transportados para as gerações seguintes, sujeitos a mudanças próprias de cada época e circunstância. (LUVIZOTTO, 2010, p. 19).
\end{abstract}

Assim, pode-se observar que o desenvolvimento da mídia em regiões de fronteira - o que, no Rio Grande do Sul, é chamada de fronteiriça e que certamente se pode também identificar em estados como Santa Catarina, Paraná, Mato Grosso, Amazonas (parte), Acre, etc., - é diversa da mídia urbana de regiões localizadas mais centralmente no território: é uma mídia bilíngue (português-espanhol, no nosso caso), com circulação e recepção multinacionais, com sentidos muito específicos, em que certamente o sentimento de diferenciação é ainda mais específico: não é nem puramente brasileira, nem puramente uruguaia, ou argentina, ou paraguaia, ou boliviana, etc.

Estas regiões que se formam histórica, cultural, econômica e socialmente acabam por desenvolver processos que, embora semelhantes em suas generalidades, apresentam-se com especificidades que precisam ser reconhecidas, identificadas, valorizadas e devidamente estudadas e compreendidas. Daí a importância, inclusive, de estudos dirigidos especificamente ao surgimento e desenvolvimento de mídias nas diferentes regiões e até mesmo em diferentes municípios (HOHFELDT, 2002, p. 191231).

Eis um excelente programa de pesquisas que recém iniciou seu curso e que certamente trará, a quem o desenvolva, excelentes resultados e surpresas. Desde 2008, quando se celebrou o bicentenário do surgimento da imprensa brasileira, muito se avançou, mas certamente muito ainda está por ser feito.

Submetido em 19.04.2017

Aceito em 21.05.2017

REFERÊNCIAS BIBLIOGRÁFICAS

BELTRÃO, Luiz. Comunicação popular e região no Brasil. In: Anuário UNESCO/Metodista de comunicação regional, São Bernardo do Campo: Cátedra 
UNESCO de Comunicação para o Desenvolvimento Regional; Universidade Metodista de São Paulo, ano 10, n.10. p. 73-80, 2006.

CORRÊA, Roberto L. Trajetórias geográficas. Rio de Janeiro: Bertrand Brasil. 1997.

HOHLFELDT, Antonio. Fluxos nacionais e contrafluxos regionais: anotações sobre a experiência gaúcha. In: Comunicação: Veredas - Revista do Programa de PósGraduação em Comunicação, Faculdade de Comunicação, Educação e Turismo, Universidade de Marília, São Paulo, v. 1, n. 2, p. 191-231, 2002. Disponível em: $<$ http://www.unimar.br/pos/rev_D/comunicacao\%20II\%20_\%20miolo.pdf>. Acesso em: 17 abr. 2017.

JACKS, Nilda. Mídia nativa - indústria cultural e cultura regional. Porto Alegre: EDUFRGS. 1998.

KLARMANN, Herbert. Região e identidade regional: um estudo da espacialidade e representatividade regional no Vale do Rio Pardo. 1999. Dissertação (Programa de PósGraduação em Desenvolvimento Regional - Mestrado e Doutorado) - Universidade de Santa Cruz do Sul (UNISC), Santa Cruz do Sul, 1999.

LUVIZOTTO, Caroline Kraus. Rio Grande do Sul: cultura e tradições. São Paulo: UNESP; São Paulo: Cultura Acadêmica. 2010. Disponível em: $<$ http://books.scielo.org/id/cq8kr/pdf/luvizotto-9788579830884-04.pdf>. Acesso em: 17 abr. 2017.

MEYER, Augusto. Gaúcho: história de uma palavra. In: Prosa dos Pagos (1941-1959). Rio de Janeiro: Livraria São José. 1960, p. 9-42.

OLIVEN, Ruben George. A parte e o todo: a diversidade cultural no Brasil-nação. Petropólis: Vozes. 1992.

SANTIAGO, Silviano. Regionalismo(s) - aquém e além da literatura, aquém e além do Etado-nação. In: SCHÜLER, Fernando Luís; BORDINI, Maria da Glória (Org.). Cultura e identidade regional. Porto Alegre: COPESUL; EDIPUCRS. 2004, p. 93102.

VERISSIMO, Erico. Um romancista apresenta sua terra. In: Rio Grande do Sul: terra e povo._Porto Alegre: Globo. 1969, p. 242.251. 